\title{
Risks of oral sodium phosphate for pre-colonoscopy bowel preparation in children
}

\author{
Response to Drs. Hassall and Lobe
}

\section{Todd H. Baron}

Published online: 11 July 2007

(C) Springer Science+Business Media, LLC 2007

\section{Erratum to: Surg Endosc}

DOI 10.1007/s00464-007-9397-3

In the first paragraph, line 15, the quotation marks should be deleted.

In Reference 3, "Erratum" should be changed to "Addendum".

The following affiliation was inadvertently omitted for Todd H. Baron:

Chair, Standards of Practice Committee, American Society for Gastrointestinal Endoscopy

1520 Kensington Road, Suite 202

Oak Brook, IL, USA

The following authors should be included at the end of the article:

Steven D. Wexner

President, Society of American Gastrointestinal and Endoscopic Surgeons

11300 Olympic Boulevard, Suite 600

Los Angeles, CA, USA

Lester Rosen

President, American Society of Colon and Rectal Surgeons 85 W. Algonquin Rd., Suite 550, Arlington Heights, IL, USA

Springer regrets these errors.

The online version of the original article can be found under doi:10.1007/s00464-007-9397-3

T. H. Baron $(\bowtie)$

Division of Gastroenterology and Hepatology, Mayo Clinic

College of Medicine, Rochester, MN, USA

e-mail: baron.todd@mayo.edu 